\title{
Anthocyanin pigment and the influence of light on the development of cabbage seedlings
}

\section{A. SZWEYKOWSKA}

The physiological role of anthocyanin pigment in vegetative plant organs is still little known. Nevertheless, in aerial shoots, this pigment is doubtless of importance for light reactions of the plant organism their occurence in epidermis or subepidermal layers at least changes the intensity and spectral composition of light which acts on the organism.

There are some data on the chlorophyll content and photosynthesis of red and pure green plant forms. These data are various and, as G a b r i e ls en (1940) emphesizes, the intensity of light used is of great importance for the results of those investigations, concerning especially the rate of photosynthesis. In superoptimal light intensity the photosynthesis of red leaves may be as high or even higher then that of green leaves and the real physiological influence of anthocyanin content will be revealed only in suboptimal light intensity.

Some authors have observed a coincidence between the appearing of anthocyanin and some phenomena of morphogeny and development. W i throw et al. (1953) observed in Phaseolus and Zea seedlings a distinct parallelism between anthocyanin content in plants and photomorphogenic responses as, above all, the increase of fresh weight of leaves. Jermoła jewa and $\mathrm{Szczeg} ł 0 \mathrm{wa}$ (1948) investigated the connection between anthocyanin production and the phase of development determined by photoperiod. These authors stated that the appearence and disappearence of anthocyanin in the leaves or the quantitative changes of it may be a criterion of the developmental phase of investigated plants Perilla nankinensis and Perilla ocymoides.

In the present study the role of anthocyanin pigment in photomorphogenic plant reactions is investigated. For this purpose the growth response, pigment synthesis and dry matter production are estimated in seedlings of red and white cabbage (Brassica oleracea var. capitata) in 
light of various spectral composition: 1) in the spectrum range which is absorbed by rubrobrassicin (yellow-green) and 2) in the spectrum range which is transmitted by rubrobrassicin (blue and red).

White and red cabbage are forms which belongs to the same species and variety. Morphologically there is no difference between them. Also the difference of ability to anthocyanin synthesis is only of quantitative nature, because in special conditions, for instance by low night temperature, in seedlings of the white cabbage appear also traces of red pigment. This difference between the white and red cabbage is then such, that the production of rubrobrassicin is facultative in the one form and obligatory in the other. In red cabbage we observe presumably a balance of metabolism shifted on the side of the secondary metabolism, together with a decrease of the intensity of primary metabolism which is among others represented by plasma synthesis and generally by growth (it is a well known fact that the red form never attains the weight and bulk attained by the white form of cabbage). It is consequently assumed that the type of metabolism and of reaction to environmental factors are identical in red and white forms of cabbage. That a comparison of these two forms is possible shows also the type of reaction to the light of different spectral composition, which in the phase of epicotyl and leaves development, when the red pigment is almost absent, is qualitatively identical in both white and red forms, which fact is stated below in the present paper. The method of comparing red and pure green forms was also used in other investigations on the physiology of anthocyanin pigments (B l a n k 1947).

\section{MATERIAL AND METHODS}

As experimental material the seedlings of Brassica oleracea var. capitata „Czerwcówka“ and f. rubra „Haco“ were used.

The seeds after germination were transplanted to vessels containing $6.93 \mathrm{~kg}$ of quartz sand, $0.07 \mathrm{~kg}$ of peat ant the following inorganic salts (Reinhold and Kochs 1935):

$\begin{array}{ll}\mathrm{CaCO}_{3} & -1.5 \mathrm{~g} \\ \mathrm{KNO}_{3} & -1.0 \mathrm{~g} \\ \mathrm{NH}_{4} \mathrm{NO}_{3} & -1.0 \mathrm{~g} \\ \mathrm{MgSO}_{4} & -0.6 \mathrm{~g} \\ \mathrm{KH}_{2} \mathrm{PO}_{4} & -1.5 \mathrm{~g} \\ \mathrm{Fe}_{-} \mathrm{citrat} & -0.1 \mathrm{~g} \\ \mathrm{H}_{3} \mathrm{BO}_{3} & -0.005 \mathrm{~g} \\ \mathrm{MnCl}_{2} & -0.004 \mathrm{~g}\end{array}$

The sand satureted with distilled water was later watered with tap water. In these experiments the seedlings were kept in suboptimal light 
intensities and of incomplete spectral composition. In order to prevent the consequences of unfavourable light conditions, the plants were grown in these experimental conditions as short a time as possible. Therefore, the experiments on the influence of light on the development of cotyledons and hypocotyl were undertaken with seedlings immediately after planting them in the sand culture, while in the experiments on the influence of light on the development of epicotyl and leaves, the seedlings with developped plumula were used, which previeously, during the first two weeks, had been grown in the normal glass-house conditions.

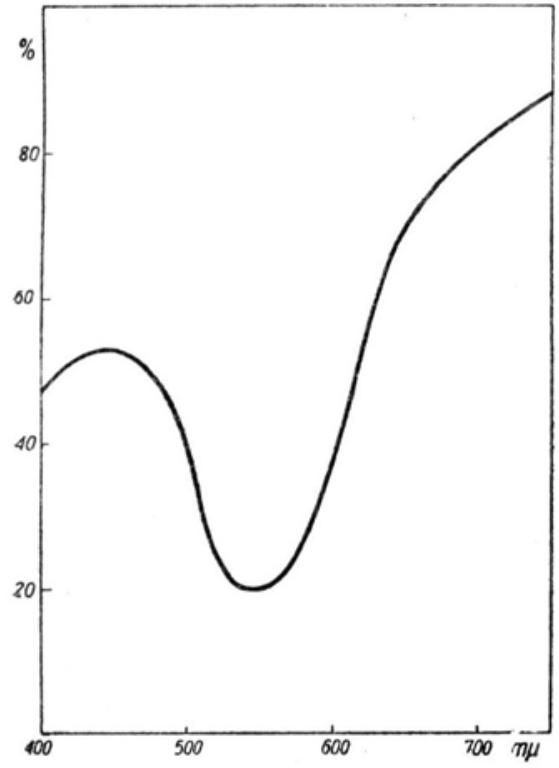

1

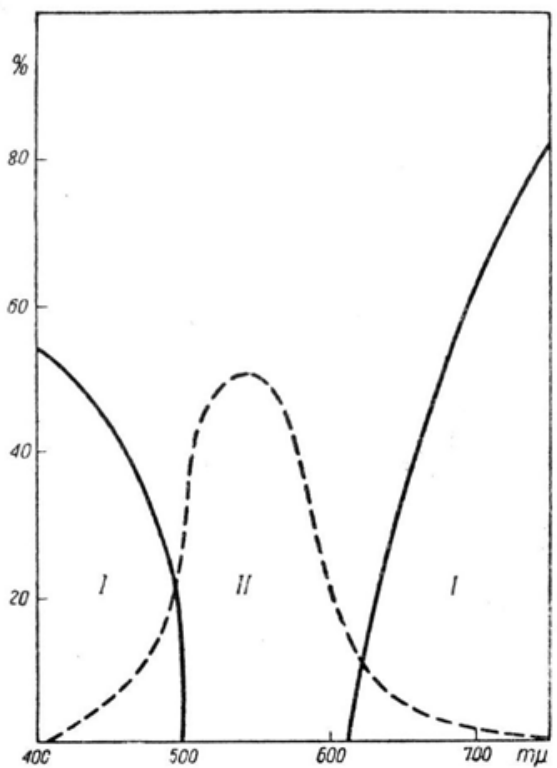

2

Fig. 1-2. Percent light transmittancy of: $1-$ rubrobrassicin solution $(\mathrm{pH}=5,5), 2-$ gelatin filters.

The culture vessels with seedlings were placed in three chambers enameled white inside and black outside and equipped with irradiation system which consisted of $1000 \mathrm{~W}$ bulb lamps and dyed gelatin filters. The cooling system consisted of a primary running water filter and of a blower which from time to time forced air through the chambers. The dyed gelatin filters were prepared by an usual technique (H ü bl 1927, Withrow 1953, Smith 1946). The dyes and their concentrations were chosen according to their spectral light transmission (the numbers after dye-names indicate the quantity of dye, in grams, which falls to $1 \mathrm{~m}^{2}$ of the filter surface):

I. Rhodamin $1,0+$ Crystal violet 0,2

II. Naphtal green $1,5+$ Tartrazine 0,2 . 
The transmission curves of radiation filters and of rubrobrassicin are given in figures 1 and 2 . The dyed filters were used together with glass atermic filters of Höppler's lamps. The amounts of light energy were identical in all irradiation treatments. The light was measured with Lange photoelement, the spectral sensibility whereof was previously determined for each irradiation system, by comparing it with a thermoelement (Zeiss). The seedlings were exposed to light during ten days, the irradiation period was $18 \mathrm{hrs}$. as the most suitable length of the daily light period for cabbage (Klesz n in 1954). The controls were kept in continuous darkness. The temperature was maintained at ca. $20^{\circ} \mathrm{C}$.

The experiments were repeated twice, each result is an average for 30 seedlings.

In analysing the results the following indications were kept in mind: the lengths of hypocotyl, stem (above cotyledons) and petioles; the fresh and dry weights of cotyledons, leaves, hypocotyl and stem; and the pigment production: chlorophyll, carotene and anthocyanin (rubrobrassicin).

\section{Pigment analysis}

Chlorophyll and carotene. The fresh plant material was macerated and the pigments extracted with acetone. Chlorophyll in acetone extract was colorimetrically determined in Pulfrich photometer using the no. 3 filter $\left(1=\right.$ ca $\left.665 \mathrm{~m}^{\mu}\right)$. The pigments were subsequently transferred to petroleum ether in a separatory funnel. After accurate washing with water the ether extract was passed through a column of $\mathrm{Mg} \mathrm{CO}_{3}$ ( $\mathrm{Z} \mathrm{e} \mathrm{c} \mathrm{h-}$ meister 1953). Carotene was then estimated in the filtrate, in Pulfrich photometer, using the no. 8 filter $(1=$ ca $465 \mathrm{m \mu})$.

Anthocyanin. The macerated plant material was extracted with $\mathrm{HCl} / \mathrm{KCl}$ buffer solution at $\mathrm{pH} 2,04(6,71 \mathrm{~g} \mathrm{KCl}$ in 11 of $\mathrm{n} / 100 \mathrm{HCl})$ and the extract was measured in Pulfrich photometer using the no. 6 filter $(1=$ ca. $533 \mathrm{mu}) \quad($ Frey-Wyssling and Blank 1943).

\section{RESULTS}

Dry matter production and pigment synthesis.

The pigment synthesis may, to a certain degree, represent an evidence of the intensity of secondary processes in the metabolism. The analytical results showed that in all conditions the red form of cabbage, besides anthocyanin production, produces also greater amounts of other pigments - chlorophyll and carotene (table no. 1).

The chlorophyll and carotene synthesis is generally higher in greenyellow light and the anthocyanin production is higher in the blue-red light, according to earlier investigations of the author ( $\mathrm{Sz}$ w e y k o w$\mathrm{sk}$ a $1954 \mathrm{~A})$. 
T a ble 1

Pigment content in $\mu \mathrm{g} / \mathrm{g}$ fresh weight

\begin{tabular}{|c|c|c|c|c|c|c|c|c|}
\hline \multirow[b]{2}{*}{ Light } & \multirow{2}{*}{$\begin{array}{c}\text { Form } \\
\text { of } \\
\text { cabbage }\end{array}$} & \multicolumn{3}{|c|}{ Leaves } & \multicolumn{3}{|c|}{ Cotyledons } & \multirow{2}{*}{$\begin{array}{l}\text { Hypocot. } \\
\text { antho- } \\
\text { cyanin }\end{array}$} \\
\hline & & $\begin{array}{l}\text { chloro- } \\
\text { phyll }\end{array}$ & $\begin{array}{l}\text { caro- } \\
\text { tene }\end{array}$ & $\begin{array}{l}\text { antho- } \\
\text { cyanin }\end{array}$ & $\begin{array}{c}\text { chloro- } \\
\text { phyll }\end{array}$ & $\begin{array}{l}\text { caro- } \\
\text { tene }\end{array}$ & $\begin{array}{l}\text { antho- } \\
\text { cyanin }\end{array}$ & \\
\hline \multirow{2}{*}{$\begin{array}{l}\text { blue- } \\
\text { red }\end{array}$} & white & 850 & 20 & 0 & 460 & 15 & 0 & 0 \\
\hline & red & 1430 & 23 & traces & 780 & 18 & 1600 & 1400 \\
\hline \multirow{2}{*}{$\begin{array}{l}\text { yellow- } \\
\text { green }\end{array}$} & white & 1010 & 22 & 0 & 420 & 12 & 0 & 0 \\
\hline & red & 2110 & 20 & traces & 910 & 39 & 1400 & 700 \\
\hline
\end{tabular}

The dry matter production, however, which represents the intensity of primary metabolism, is, as would be expected, lower in seedlings of red cabbage. In all conditions the dry matter content of one seedling, expressed in mgs, is higher in white cabbage (table no. 2).

Table 2

Dry matter production in $\mathrm{mg} /$ seedling

\begin{tabular}{l|l|c|c}
\hline \multicolumn{1}{c|}{ Light } & Form of cabbage & $\begin{array}{c}\text { Hypocotyl and } \\
\text { cotyledons }\end{array}$ & Epicotyl and leaves \\
\hline \multirow{2}{*}{ dark } & white & 3,8 & 3,1 \\
& red & 2,6 & 2,2 \\
\hline \multirow{3}{*}{ blue-red } & white & 3,4 & 7,9 \\
& red & 2,6 & 4,9 \\
\hline \multirow{3}{*}{ yellow-green } & white & 3,2 & 9,5 \\
& red & 3,1 & 5,5
\end{tabular}

The influence of different light conditions on the dry matter production and dry matter distribution will be discussed together with other growth reactions in the next chapter.

\section{Growth responses}

Following growth responses were taken into consideration: the lengths of hypocotyl, epicotyl and petioles and the fresh and dry weight distribution in seedlings under various light conditions.

The experiments showed, that the photomorphogenic responses of white and red seedlings are qualitatively identical in the second phase of development (development of stem and leaves, table no. 5-6) and diverse in the first phase (development of hypocotyl and cotyledons, tables no. 3-4). In both forms the shortening of hypocotyl is greater in 
Ta ble 3

Growth responses of hypocotyl

\begin{tabular}{l|l|c|c|c|c}
\hline $\begin{array}{l}\text { Form of } \\
\text { ca bbage }\end{array}$ & \multicolumn{1}{|c|}{ Light } & $\begin{array}{c}\text { length } \\
\text { mm }\end{array}$ & $\begin{array}{c}\text { fr. weight } \\
\text { mg }\end{array}$ & $\begin{array}{c}\text { dry weight } \\
\text { mg }\end{array}$ & $\begin{array}{c}\text { fr. w. / length } \\
\text { mg/cm }\end{array}$ \\
\hline \multirow{3}{*}{ white } & dark & 96 & 71 & 2,2 & 7,4 \\
& blue-red & 75 & 50 & 1,6 & 6,7 \\
& yellow-green & 78 & 49 & 1,5 & 6,2 \\
\hline \multirow{3}{*}{ red } & dark & 91 & 52 & 1,6 & 5,7 \\
& blue-red & 61 & 37 & 1,2 & 6,1 \\
& yellow-green & 67 & 43 & 1,4 & 6,4
\end{tabular}

the blue-red light (table no. 3). Moreover, in the white form also other growth reactions, such as the fresh and dry weight of hypocotyl and of cotyledons, are stronger in the blue-red light and the etiolation grade of hypocotyl (expressed in mgs of fresh weight per $1 \mathrm{~cm}$ of length) is weaker in this light as compared with the light of yellow-green range (table no. 3). Instead, the reactions of the red form are of another nature. The etiolation grade of hypocotyl is weaker in the light of yellow-green range and its fresh and dry weight is higher (table no. 3). The fresh weight of cotyledons is a little lower in the yellow-green light, but its dry weight is here also higher (table no. 4).

Table 4

Growth responses of cotyledons

\begin{tabular}{l|l|c|c}
\hline \multirow{2}{*}{ Form of cabbage } & \multicolumn{1}{|c|}{ Light } & $\begin{array}{c}\text { Fresh weight } \\
\mathrm{mg}\end{array}$ & $\begin{array}{c}\text { Dry weight } \\
\mathrm{mg}\end{array}$ \\
\hline \multirow{3}{*}{ white } & dark & 16 & 1,6 \\
& blue-red & 45, & 1,8 \\
& yellow-green & 35 & 1,7 \\
\cline { 2 - 3 } red & dark & 9 & 1,1 \\
& blue-red & 30 & 1,5 \\
& yellow-green & 29 & 1,6
\end{tabular}

It follows that in the first phase of development (hypocotyl and cotyledons) the morphogenic responses of the white form are stronger in the blue-red light and the growth responses of the red form are for the most part (the fresh and dry weight of hypocotyl, its etiolation grade, dry weight of cotyledons) stronger in the light of yellow-green range. 
In the phase of epicotyl development both forms of cabbage seedlings behave in the same manner. The growth of stem (above cotyledons) is more intensive in the blue-red light, its length and weight in this light is higher and the etiolation grade lower $(\mathrm{mg} / \mathrm{cm}$. table no. 5). On the

$\mathrm{T}$ a ble 5

Growth responses of the stem

\begin{tabular}{l|l|c|c|c}
\hline $\begin{array}{c}\text { Form of } \\
\text { cabbage }\end{array}$ & \multicolumn{1}{|c|}{ Light } & $\begin{array}{c}\text { Length } \\
\mathrm{mm}\end{array}$ & $\begin{array}{c}\text { Fresh weight } \\
\mathrm{mg}\end{array}$ & $\begin{array}{c}\text { Fr. w. / length } \\
\mathrm{mg} / \mathrm{cm}\end{array}$ \\
\hline \multirow{3}{*}{ white } & dark & 3 & 6 & 20,0 \\
& blue-red & 24 & 44 & 18,2 \\
& yellow-green & 16 & 27 & 16,9 \\
\hline \multirow{3}{*}{ red } & dark & 5 & 6 & 12,0 \\
& blue-red & 34 & 35 & 10,3 \\
& yellow-green & 25 & 24 & 9,6
\end{tabular}

contrary, for the development of leaves the yellow-green light proves to be much more effective. This is marked distinctly in the fresh and dry weight of leaf blades and also indicated in the etiolation grade of petioles (table no. 6).

T a b l e 6

Growth responses of leaves

\begin{tabular}{|c|c|c|c|c|c|c|c|}
\hline \multirow{2}{*}{$\begin{array}{c}\text { Form } \\
\text { of } \\
\text { cabbage }\end{array}$} & \multirow[b]{2}{*}{ Light } & \multicolumn{3}{|c|}{ Leaf blade } & \multicolumn{3}{|c|}{ Petioles } \\
\hline & & $\begin{array}{l}\text { fr. w. } \\
\text { mg }\end{array}$ & $\begin{array}{c}\text { dry w. } \\
\text { mg }\end{array}$ & $\underset{\substack{\alpha \\
\phi}}{\operatorname{dry}} \mathrm{w}$. & $\begin{array}{l}\text { length } \\
\mathrm{mm}\end{array}$ & $\begin{array}{l}\text { fr. w. } \\
\text { mg }\end{array}$ & $\begin{array}{l}\text { fr. w./ } \\
\text { length } \\
\mathrm{mg} / \mathrm{cm}\end{array}$ \\
\hline \multirow{3}{*}{ white } & dark & 19 & 2,3 & 12,1 & - & - & - \\
\hline & blue-red & 82 & 4,2 & 5,1 & 27 & 62 & 22,9 \\
\hline & yellow-green & 126 & 6,6 & 5,2 & 24 & 57 & 23,8 \\
\hline \multirow{3}{*}{ red } & dark & 13 & 1,1 & 8,5 & - & - & - \\
\hline & blue-red & 28 & 2,1 & 7,5 & 21 & 28 & 13,3 \\
\hline & yellow-green & 48 & 3,4 & 7,1 & 19 & 26 & 13,7 \\
\hline
\end{tabular}

It is interesting that the great, qualitative differences in the growth responses on the different spectrum ranges between white and red seedlings appear only in the first phase of development, when the one form of seedlings produces great quantities of anthocyanin pigment. This pigment appears mainly in the hypocotyl that is in the organ in which these growth differences are most distinct. In the phase of stem and leaves 
development of the red form there are only slight traces of anthocyanin pigment in the neighbourhood of the petiole base and of main veins of the leaves. Simultaneously, in this phase, the growth responses of the red form to the spectral light composition are qualitatively the same as the responses of the white form.

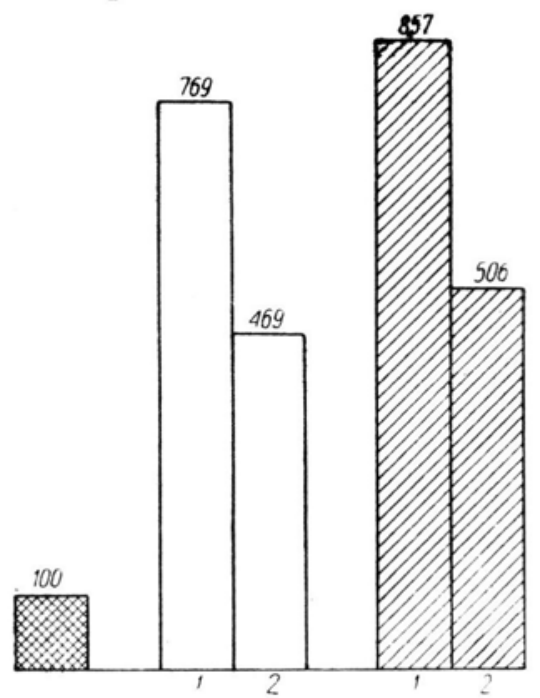

Fig. 3. Dry weight of stem and leaves.

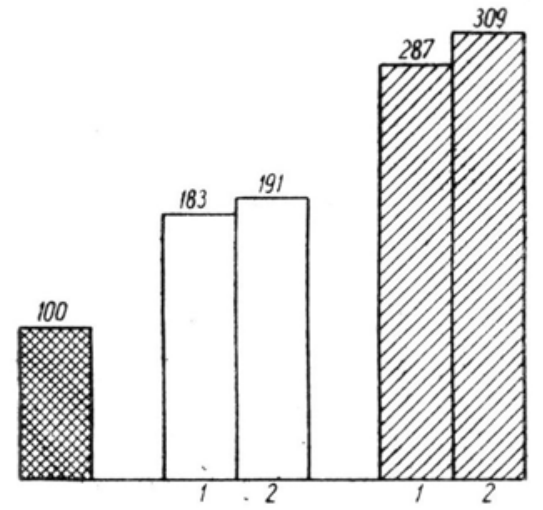

Fig. 4. Dry weight of leaf blades.

Fig. 3-6. Checked blocks at left: darkness, white blocks: blue-red light, lined blocks at right: yellow-green light. 1 - white cabbage, 2 - red cabbage.

However, the differences in pigment content between both forms of cabbage seedlings concern not only anthocyanin. There exist distinct quantitative differences in the chlorophyll and also carotene content. It seems to be possible that there also exist differences in the quantitative relations of some photomorphogenic reactions possibly caused by a different pigment concentration. The direct values of measurements are generally higher for the white cabbage, which, as was supposed, is caused by a more intensive primary (growth) metabolism of the white form. Thus only the relative growth values can answer the question as to the influence of different amounts of pigment on the photomorphogenic responses of the white and red cabbage seedlings. Figures no. 3-6 represent some more interesting percent values of several growth responses, taking the dark values as equal to 100 .

The relative distribution of dry weight between leaf blades, stem and petioles is an interesting difference between both forms. The total relative dry matter production (of the whole plant above cotyledons) is higher in the white form (fig. no. 3). But the distribution of this dry matter is such, that for the red form the increase of dry weight is relatively high in the 
leaf blades (fig. no. 4), and for the white form in the stem and petioles (fig. no. 5). The relative high increase of dry weight of leaf blades of the red form does not correspond to an analogical proportion of fresh weight increase which is much higher for the white form (fig. no. 6). This fact is connected with a much lower water content in the leaf blades of the red form (table no. 6).

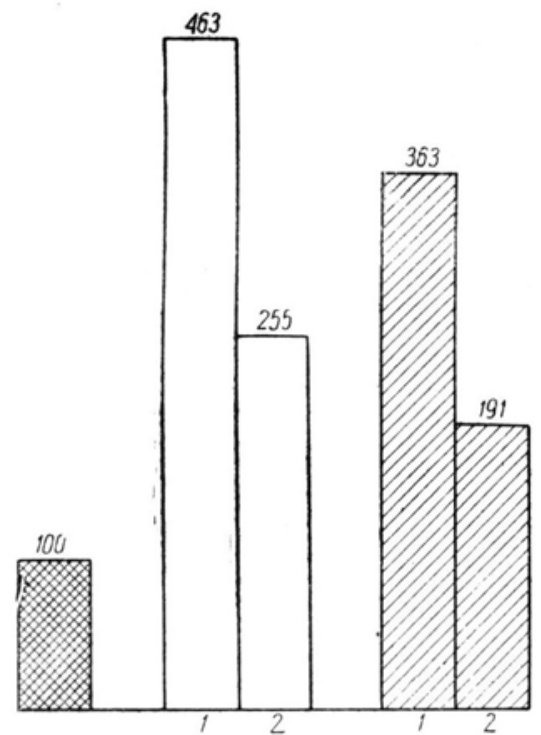

Fig. 5. Dry weight of stem and petioles.

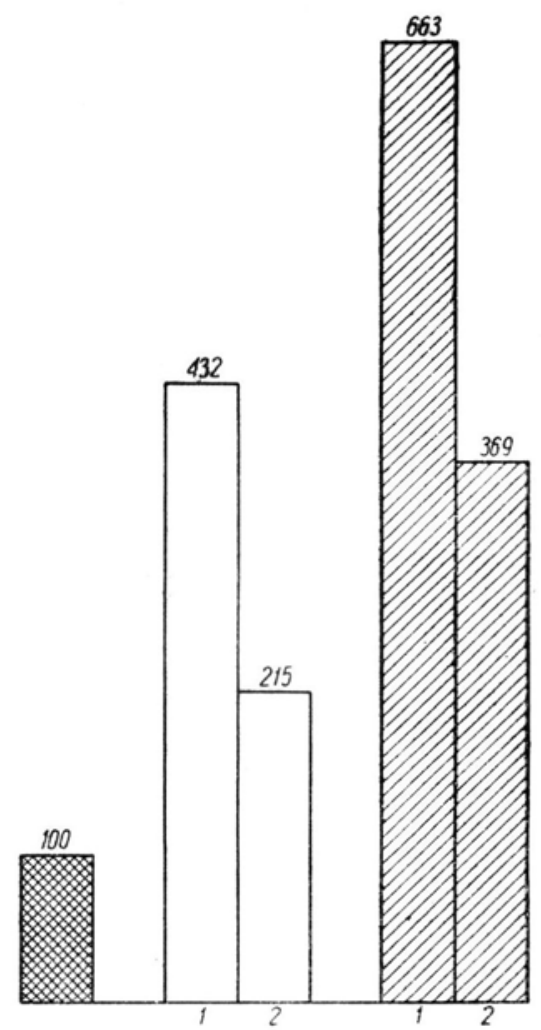

Fig. 6. Fresh weight of leaf blades.

In this way, a higher content of chloroplast pigments in the leaves of the red cabbage form corresponds to a relatively high dry weight increase of the leaves.

\section{DISCUSSION}

The experiments proved a high effect of yellow-green light for the development of cabbage seedlings, especially on the development of epicotyl and leaves (table no. 2 nad 6). These results agree with the statements of M s z k ow $(1950,1953)$, who reported that for the development of many plants cultivated in artificial light the yellow-green range of light is the most favourable and that by lower light intensities the efficiency quotient is the highest for this light range. 
It is interesting that in the first phase of seedling development, when the plants still develop mainly at the expense of cotyledonary food reserves, the photomorphogenic response of anthocyanin red form is stronger than that of the white form, especially in the light of yellowgreen range, the action of which on the white form is altogether weak in this phase. This would indicate that anthocyanin pigment acts stimulatingly on the seedling development and that in this process it plays the part of some kind of light absorber in photomorphogenic reactions. In the later phase of development, when photosynthesis is of great importance, the red pigment acts as a light filter, diminishing, by lower light intensities, the rate of photosynthesis, as it is stated by G a b r i e ls e n (1940).

\section{SUMMARY}

The development of seedlings of white and red cabbage (Brassica oleracea var. capitata) in the light of blue-red and of yellow-green spectrum ranges has been investigated. The photomorphogenic responses of red seedlings are in the first phase of development different from those of white seedlings and, inversely to them, stronger in the yellow-green light. This would speak in favour of the view that anthocyanin pigment acts stimulatingly on the seedling development and that in this process it plays the part of a light absorber in photomorphogenic reactions. In the later phase of development, when photosynthesis is of great importance, the red pigment acts as a light filter, diminishing, by lower light intensities, the rate of photosynthesis, as it is stated by G a b r i e ls e n (1940).

Institute of Plant Physiology

University of Poznań

(Entered 10.XII.1956)

\section{LITERATURE}

B lank F., 1947, The anthocyanin pigments of plants, Bot. Rev. 13: 241-317.

Frey-Wyssling A., und Blank F., 1943, Untersuchungen über die Physiologie des Anthocyans in Keimlingen von Brassica oleracea L. var. capitata L. f. rubra (L.), Ber. Schweiz. Bot. Ges. 503a: 550-578.

H übl A., 1927, Die Lichtfilter, W. Knapp, Halle.

Jermoła jewa J. J. i Szczeg łow a O. A., 1948, Antocyjan i razwitie rastienij, DAN SSSR, 60: 901-903.

Klesznin A. F., 1954, Rastienije i swiet. Izd. Ak. Nauk SSSR.: 304 Moskwa.

Moszkow B. S., 1950, Znaczenie otdielnych uczastkow spektra fizjołogiczeskoj obłasti izłuczenia dla rosta i razwitia niekatorych rastienij, DAN SSSR 71: 171-174.

M o s z k ow B. S., 1953, Wyraszczywanie rastienij na isskustwiennom oswieszczenii, Sielchozgiz, 171: 90-122 Moskwa.

Paech K., 1950, Biochemie und Physiologie der sekundären Pflanzenstoffe, Springer-Verlag, Berlin. 
Reinhold J. und Kochs H., 1935, Der Einfluss der Düngung auf Ertrag und Qualität des Kohles, Zeitschr. Pfl. Ern., Düng. u. Bodenkde 39: 198-211.

$\mathrm{S}$ mith B., 1946, Method for making filters transmitting the near ultraviolett and absorbing visual light, Science 104: 490-491.

Szweykowska A., 1955, The influence of light on the biogenesis of rubrobrassicin in seedlings of red cabbage, Acta Soc. Bot. Pol. 24: 13-26.

Szweykowska A., 1956, Anthocyaninpigmente der Pflanzen und ihre Physiologie, Zeszyty Naukowe Uniwersytetu im. A. Mickiewicza: 69-96.

Withrow R. B., Kle in W. H., Price L., Elstad V., 1953, Influence of visible and near infrared radiant energy on organ development and pigment synthesis in bean and corn, Plant Physiology, 28: 1-14.

Withrow R. B. and Price L., 1953, Filters for the isolation of narrow regions in the visible and near-visible spectrum, Plant Physiology 28: 105-114.

Z e chmeister L., 1953, Progress in chromatography, Chapman Hall LTD: 73 London. 